Provided for non-commercial research and education use. Not for reproduction, distribution or commercial use.

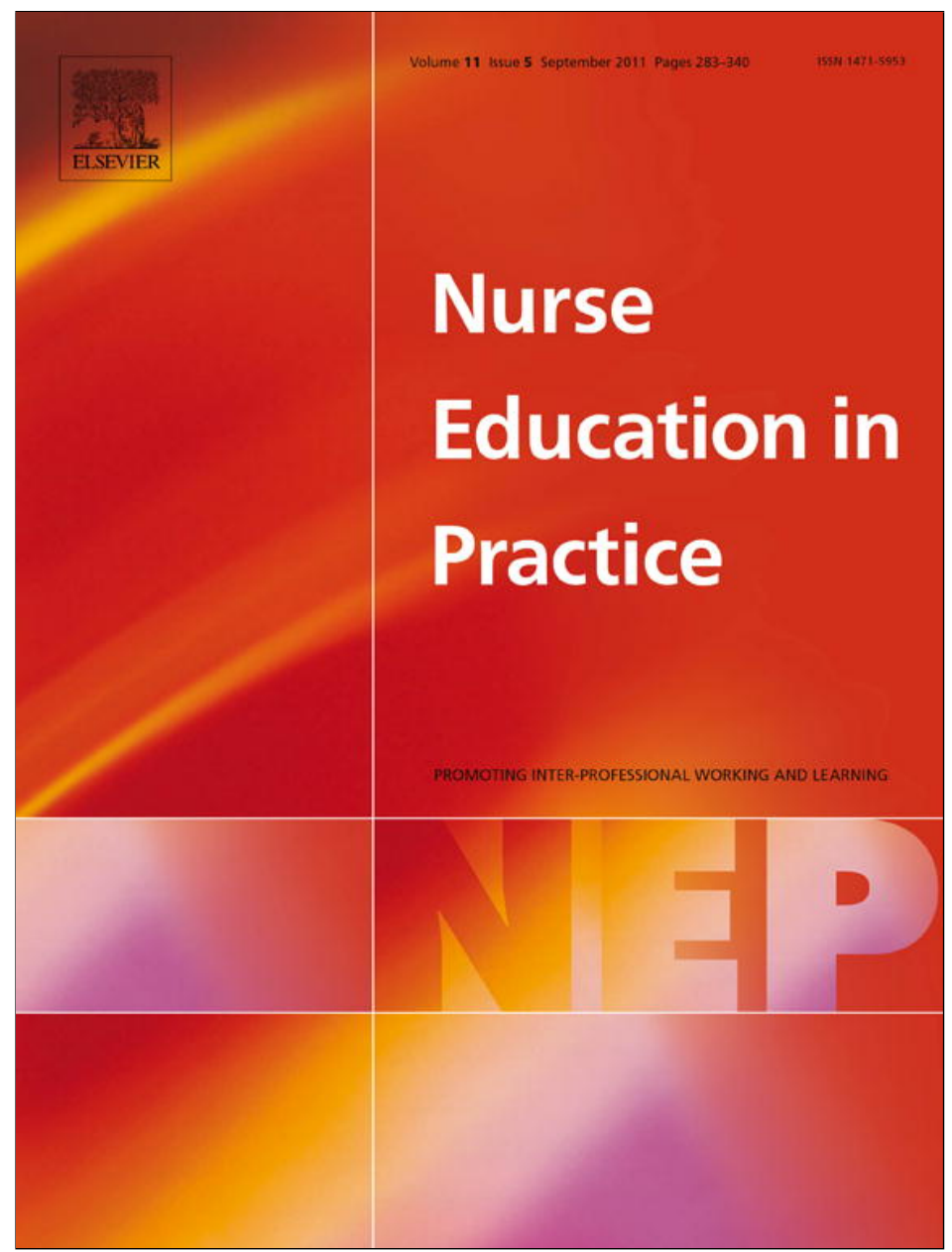

This article appeared in a journal published by Elsevier. The attached copy is furnished to the author for internal non-commercial research and education use, including for instruction at the authors institution and sharing with colleagues.

Other uses, including reproduction and distribution, or selling or licensing copies, or posting to personal, institutional or third party websites are prohibited.

In most cases authors are permitted to post their version of the article (e.g. in Word or Tex form) to their personal website or institutional repository. Authors requiring further information regarding Elsevier's archiving and manuscript policies are encouraged to visit:

http://www.elsevier.com/copyright 


\title{
The team builder: The role of nurses facilitating interprofessional student teams at a Swedish clinical training ward
}

\author{
Carlson Elisabeth $^{\mathrm{a}, *}$, Pilhammar Ewa ${ }^{\mathrm{b}}$, Wann-Hansson Christine ${ }^{\mathrm{a}}$ \\ ${ }^{a}$ Malmö University, Faculty of Health and Society, Department of Nursing, Sweden \\ ${ }^{\mathrm{b}}$ University of Gothenburg, The Sahlgrenska Academy, Institute of Health and Care Sciences, Sweden
}

\section{A R T I C L E I N F O}

\section{Article history:}

Accepted 2 February 2011

\section{Keywords:}

Interprofessional education

Clinical training ward

Facilitating nurses

Ethnography

\begin{abstract}
A B S T R A C T
Interprofessional education (IPE) is an educational strategy attracting increased interest as a method to train future health care professionals. One example of IPE is the clinical training ward, where students from different health care professions practice together. At these wards the students work in teams with the support of facilitators. The professional composition of the team of facilitators usually corresponds to that of the students. However, previous studies have revealed that nurse facilitators are often in the majority, responsible for student nurses' profession specific facilitation as well as interprofessional team orientated facilitation. The objective of this study was to describe how nurses act when facilitating interprofessional student teams at a clinical training ward. The research design was ethnography and data were collected through participant observations and interviews. The analysis revealed the four strategies used when facilitating teams of interprofessional students to enhance collaborative work and professional understanding. The nurse facilitator as a team builder is a new and exciting role for nurses taking on the responsibility of facilitating interprofessional student teams. Future research needs to explore how facilitating nurses balance profession specific and team oriented facilitating within the environment of an interprofessional learning context.
\end{abstract}

(c) 2011 Elsevier Ltd. All rights reserved.

\section{Background}

Collaboration and team work has been recognised by WHO (2006) as vital strategies to overcome the challenges facing the global health care work force due to a worldwide shortage of doctors, midwives and nurses. Increased collaboration is thus seen as a way to enable comprehensive patient centred health care with high quality outcomes (Begley, 2009). For this reason, interprofessional education (IPE) defined by Barr et al. (2005) as "occasions when two or more professions learn with, from and about each other to improve collaboration and the quality of care" (p.xv) is an educational strategy attracting heightened interest globally as a mean to train future health care professionals and thus enhance team work, improve communication and break down territorial barriers (Morrison et al., 2003; Carlisle et al., 2004; Ponzer et al., 2004).

Interprofessional education has been implemented in several different settings and with varying compositions of students and facilitators taking part in the IPE experience, and can take place in class rooms as well as in clinical settings (Cooper et al., 2001;

\footnotetext{
* Corresponding author. Tel.: +46 406657451 .

E-mail address: elisabeth.carlson@mah.se (C. Elisabeth).
}

Oandasan and Reeves, 2005). During IPE, proficient facilitators have been shown to be of vital significance for students' learning experiences, and facilitators need to address issues that involve team formation as well as team maintenance (Oandasan and Reeves, 2005; Hammick et al., 2007). This is quite a demanding form of facilitating as teaching groups composed of students from different professions requires knowledge of content as well as process so learning can be achieved (Anderson et al., 2009). IPE within hospital settings implemented as clinical training wards (CTW) has increased over the last 20 years. In Sweden, the Faculty of Health and Society at Linkoping University should be credited as fore runner for this educational strategy and the "Linkoping model" has been implemented at a number of hospitals in Sweden (Wahlström and Sanden, 1998; Mogensen et al., 2002; Hylin et al., 2007), in England (Reeves and Freeth, 2002) and in Denmark (Jacobsen et al., 2009). With continuous support from facilitators, students from different health care professions work in teams with a high degree of clinical independence. The different professions represented by the IPE facilitators usually correspond to that of the students in terms of which educational health care programme the students represent (Wahlström et al., 1997). However, more recent studies (Freeth et al., 2001; Reeves et al., 2002; Hylin et al., 2007) reveal that nurses often are in the majority hence providing profession specific as well as team oriented facilitation. How this is 
carried out by the nurses is not well described in the literature, and few empirical studies about facilitators' experiences of delivering IPE exist (Lindqvist and Reeves, 2007). For the current study no empirical studies were found exploring interprofessional facilitating from the perspective of facilitating nurses. Therefore; to gain a deeper understanding of facilitating as an important aspect of successful IPE, an ethnographic study was undertaken with the specific aim to describe how nurses act when facilitating interprofessional student teams at a clinical training ward.

\section{Methods}

This study was guided by symbolic interactionism (Blumer, 1969; Hammersley and Atkinson, 2007). The chosen approach was seen as appropriate as it enables in depth studies on how facilitating nurses act in the social setting of an interprofessional clinical training ward.

\section{Setting}

The study took place at the CTW at a University hospital in southern Sweden. The CTW was located on a 40-bed medical ward of which eight beds were used for the clinical training ward. The patients at the CTW were usually elderly in need of general medical, nursing and rehabilitation care, and before admission to the ward all patients received verbal and written information. During a 2 week long clinical placement, undergraduate students representing medicine (in term eight of eleven), nursing, physiotherapy (PT) and occupational therapy (OT), in term five or six final year, work and learn together as a team. At the time of the study this clinical placement was a course requirement for medical and nursing students but an elective course for OT and PT students. The composition of each student team were typically made up of one or two medical students, three to four nursing students and one PT and/or OT student. Each team worked on a rota, planning and delivering patient care, and students were expected to share all basic patient care in addition to their profession specific duties. The student teams were facilitated during day shifts ( $7 \mathrm{am}-4 \mathrm{pm})$ by a team of facilitators (one senior consultant, two nurses, one occupational therapist and one physical therapist), thus receiving profession specific as well as team oriented facilitating. However, during evening shifts $(1.30 \mathrm{pm}-9.30 \mathrm{pm})$ and both shifts on weekends, nurses were the only profession facilitating the teams. During these times, one nurse was facilitating one student team/ shift with the opportunity to contact the doctor on call at all times.

\section{Data collection}

Following the ethnographic approach, data were primarily collected by participant observation (Hammersley and Atkinson, 2007), with the first author present in the field during the six month long observational period from March to September 2009. During the field work period all nurse facilitators employed at the CTW were asked to participate $(n=8)$. They were considered to be knowledgeable specialists within the researched area, hence the principals of judgemental sampling was performed (Agar, 2008). The role of the researcher has strictly been that of the participant observer i.e. being known by the participants but not participating in any facilitating or clinical situation. Observations were focused around interactions between nurse facilitators and the student teams. When an observed situation needed clarification, informal conversation took place between researcher and facilitator. The field work included $50 \mathrm{~h}$ of observation, covering day and evening shifts. Each observational session lasted between $1 \frac{1}{2}-5 \mathrm{~h}$ depending on the activities taking place. Extensive observational field notes recording events, actors, time, and place as well as analytical reflective notes were written down during observations. Short after a completed shift, field notes were transcribed into a neat copy to guide coming observations and analysis.

To deepen and expand the range of perspectives and experiences of the facilitating nurses, individual interviews and one concluding focus group interview were performed. This strategy holds the potential to compare what is told individually and during group discussions (Lambert and Loiselle, 2008). All eight observed facilitators accepted to take part in the individual interview and four out of these eight facilitators accepted to participate in the focus group interview (Table 1). Reasons for not participating were of a private nature such as vacation or sick leave. The interviews were conducted either at the hospital where the facilitators worked or in a conference room at the affiliated university subject to participant convenience. A digital voice recorder was used. Individual interviews lasted approx. $56 \mathrm{~min}$ (43-63 $\mathrm{min}$ ) and the focus group interview for nearly $2 \mathrm{~h}$. The individual interviews started with one open question namely: "Please tell me what you think is typical when you are facilitating at the CTW". The nurses were encouraged to talk quite freely and follow up questions were put to them, to clarify or exemplify their experiences. To guide the discussion in the focus group, following themes that had emerged during preliminary analysis were used as a starting point; Independence, Sense of Security and Team.

The principals of professional secrecy for health care personnel in accordance with Swedish law have been followed by the researcher. Ethical approval was granted from the Regional Board of Ethical vetting in Southern Sweden (Dnr 590/2006) before the study commenced.

\section{Analysis}

The final analysis started by reading all field notes and transcribed texts from the interviews several times to gain a general sense of and openness to data. The tapes from the interviews were listened to repeatedly to ensure that transcriptions were complete and accurate. As the analysis proceeded, all text was converged and read as a whole. Guiding the reading was the search for meaning units illustrating actions and experiences of facilitating nurses. The meaning units were coded for content and sorted into categories, and the meaning of each category was explained and clarified. The constant comparative method (Glaser and Strauss, 1967; Hammersley and Atkinson, 2007) was used so that each item of data could be compared to other data categorised in the same way, allowing for new categories to emerge. The emerging findings have been discussed and agreed upon by the three authors during the research process until the criteria of redundancy was reached.

\section{Trustworthiness}

Credibility was ensured by using data from both field work and interviews, inferences from different sources were hence checked and compared (Hammersley and Atkinson, 2007). Another step

Table 1

Participants.

\begin{tabular}{lll}
\hline & $\begin{array}{l}\text { Field work and } \\
\text { Individual Interviews }\end{array}$ & Focus group \\
\hline Number of participants & 8 & 4 \\
Professional experience & $3-91 / 2$ year & $3-6$ years \\
Experience as facilitator & $2-8$ years & $2-4$ years \\
Age & $27-49$ years & $27-49$ years \\
Sex & $F=7$ & $F=4$ \\
& $M=1$ & \\
\hline
\end{tabular}


taken was respondent validation, when a summary of findings from preliminary analysis was presented to the focus group as a starting point for the discussion. Participating nurses agreed and recognised that the findings presented an accurate picture of their practices as facilitators. It is also important to raise the question of the insider perspective (Hammersley and Atkinson, 2007). The field work allowed the researcher (EC) to share the every day activities with a group of nurses. This is an environment well known to the researcher who has extensive clinical experience as a nurse and facilitator, however not from this particular ward or hospital, even so the familiarity might cloud the exploration of nuances and details. There is also the question of reactivity i.e. that the presence of the researcher will impact the behaviour of the studied group. For these reasons, reflective notes concerning the researcher role and the emerging findings were regularly written down during and after sessions in the field. This procedure enabled reflections and discussions among all three authors concerning reflexivity (Pellatt, 2002).

\section{Findings}

The findings illustrate the facilitating role of the nurses as that of the team builder and the four categories found should be understood as the strategies used by nurses when facilitating interprofessional student teams. The strategies were: supporting team work, facilitating professional understanding, breaking down barriers and using a reflective approach. Being a CTW facilitator was also described as a purposeful and strategic choice made by the nurses as this position allowed them more time to facilitate than what is normally allocated to nurses involved in clinical practice as facilitators.

\section{Supporting team work}

To support the students so they could work as a team was seen as a challenge for the facilitators as well as their first and foremost priority. During field work it was evident that all facilitating activities had a clear student centred approach, and that the nurses created opportunities for student teams to work independently. This implied that facilitators were not active partners of the teams or directly involved in the various team activities. Instead, nurse facilitators were encouraging independent work and cooperation.

"The facilitators' attention to the team is quite distinctive; facilitators often repeat questions such as Who in the team is doing what? Have you decided together? What are your plans?" (Field note April 2009).

Thus, facilitating was not focused towards profession specific skills and knowledge but cooperation and communication between the professions. This can be illustrated by following field note where the facilitators put the team in the centre of activities allowing them to work independently yet knowing that the facilitators were close by able to provide support if necessary.

"It's 09.30 in the morning and rounds are about to start. The facilitators have placed themselves at the end of the table, out of direct eye contact with the team, so the students can face each other while discussing their patients" (Field note March 2009).

Even if the clinical placement at the CTW was only two week long the nurses took great care in trying to identify the learning needs of the individual student. This was considered to be of vital importance as it might impact the performance of the entire team.

"The team has just started their first shift, I notice how the facilitating nurse try to find time to talk to each student to find out about previous experiences. When I ask her about this, she explains to me: If I don't get to know who they are or what they need to practice as individuals they won't be able to contribute to the team either" (Field note March 2009).

\section{Facilitating professional understanding}

This category describes the challenges nurses encountered when facilitating teams representing different professions. It was clear that nurses were aware of existing professional responsibilities and how it was important for students to understand their own profession as well as that of the other team members. To make this explicit to students, facilitators consciously directed profession specific questions from a student to a fellow student from the same profession hence facilitating peer learning as illustrated by the following quote.

/../The nurses never really answer any questions from the students, instead they try to redirect the question back to the students or ask if anyone in the team can help. As one of the facilitators explains: "I have to challenge the students as I don't have all the answers, I don't know enough about medical stuff or rehab, I need them to get to work together and learn from each other" (Field note September 2009).

The nurses also explained how important it was to be good professional role models, not only in relation to student nurses. Equally important was to act in such a way that the knowledge and skills of nurses, and hence the professional responsibilities became evident to all students.

"Hopefully I contribute to a better understanding of the different professional roles in the team when I as a nurse can illustrate what my profession is all about" (Interview 4, May 2009).

\section{Breaking down barriers}

Facilitators also stressed the importance of contributing to a break down of hierarchical barriers by making the different knowledge domains and professional responsibilities visible and understandable to students. They explained how they tried to teach the students to focus on the needs of the patient, and use that as guidance for the decisions the teams had to make regarding patient care.

"Medical students have a lot of knowledge but not really any practical experience, that might contribute to the almost non existing medical hierarchy in the teams. Instead we talk about how the knowledge most relevant for the patients' need right here and now has to guide the team's decisions" (Informal talk with facilitator 7 during field work May 2009).

Daily rounds were for the above reason considered to be fruitful settings for learning across professional barriers so that implications and effects of the students' different knowledge and skills for good patient care could be discussed.

\section{Using a reflective approach}

Reflective facilitating was shared by all nurse facilitators as an educational technique permeating all learning activities at the CTW. The reflective technique in this case implied the use of open and probing questions to enable the development of problem solving and clinical reasoning skills in students. In addition, it was seen as an absolute prerequisite to be able to facilitate students who were not student nurses as the facilitating nurses did not share 
the theoretical and practical knowledge base of medical, PT and OT students.

"Being a facilitator at a clinical training ward? That means encouraging reflection, using open ended questions to be able to meet all students. True, and by doing that we also try to promote the importance of using each other as sources of knowledge" (Focus group June 2009).

Reflective seminars were also held once a week to facilitate reflection within the student teams. Each seminar was led by two facilitators which was a shared responsibility among all professions. However, as the nurses were in the majority usually one and quite often both facilitators were nurses. The facilitators pointed to how the seminars should focus team collaboration as well as issues regarding patient care. The nurses also explained how important it was that every student in the team was listened to and being considered as an important contributor to team discussions.

"When we hold the seminars we make sure that the students focus on issues regarding the team and how they work as a team and we tell the students that every one has to contribute to something" (Interview 7 September 2009).

\section{Discussion}

Our study has illustrated the role of nurse facilitators at this CTW as that of the team builder. In the presented study the strategy supporting team work was considered by the facilitating nurses as their first priority when facilitating interprofessional student teams. This is in line with earlier studies (Oandasan and Reeves, 2005; Hammick et al., 2007; Anderson et al., 2009) where team formation and team maintenance was discussed as important areas for facilitators to focus. According to the nurses in the current study this was achieved by constantly remembering the students that all decisions regarding patient care had to be decided mutually by the team. Traditional medical hierarchies were thus viewed as a hindrance to collaboration and efficient patient care, and the nurse facilitators described how they tried to break down barriers. The nurse facilitators strived to make the different knowledge domains and professional responsibilities visible and understandable to students and pointed to how the need of the patient had to be guiding students' decision making processes. This implies that the knowledge most relevant to the situation at hand should be in focus as described by Carlisle et al. (2004). Reflection was therefore used by nurse facilitators in the current study as a mean to facilitate a deeper understanding of experienced situations related to patient care as well as to the students' professional responsibilities. Argyris and Schön (1974) discuss reflective learning in term of double-loop learning which implies that individuals or groups need to question their presently held values or assumptions in order to modify those and thus incorporate new ways of action. In the current study, the facilitating nurses promoted reflective facilitating implying the use of high level open questions as a conscious educational strategy with the intention to let students explore and learn (Hannigan, 2001). Reflective facilitating implies the continuous use of reflective dialogue between facilitator and student enabling the development of critical thinking and problem solving skills either during an activity as reflection in action (Schön, 1987) or after the experience has taken place i.e. reflection on action (ibid). This strategy is somewhat contradictory to earlier findings in a study by Carlson et al. (2009) where nurses who were facilitating in a more traditional one-to-one uniprofessional relation tended to ask more factual or low level questions. It would therefore be of interest to further explore the reasons behind the different ways to ask questions and how questioning skills can be taught in preparation programmes for facilitators.

In our study facilitators were aware of the importance of helping students acknowledge each others knowledge and skills by consistently pointing to how the different team members could learn, not only from but also with each other as peer learning was promoted by the nurses. Thus, our findings correspond to Barr et al. (2005) who promote adult learning strategies that will activate and be of practical relevance to students. Peer learning where students help each other to learn and thus learn themselves, by teaching (Topping, 1996) can be used as a means to prepare students for collaborative work. Peer learning can also be understood as a form of action learning. Jarvis (2006) defined this as learning by and from doing within a specific social context with a support group so that members can engage in reflection on their actions. When peer learning is promoted by facilitators within an interprofessional educational context this collaborative learning model hold the potential to raise students' awareness and understanding of different professional responsibilities, and should be discussed among faculty and facilitators as a viable learning strategy. Thus, by illustrating the strategies used by facilitating nurses our study provides a complementary perspective on interprofessional learning as described by O'Halloran et al., 2006 as well as Forte and Fowler (2009) who argued that a result of interprofessional learning might be that students will come to understand the boundaries and expertise of different professions as well as their own which is probably favourable for future professional collaboration.

It also needs to be noted that nurse facilitators were aware of how important it was to support students who were not student nurses at times when their profession specific facilitators were not present. From the perspective of medical students, Hylin et al. (2007) reported how they wanted more profession specific feed back from their medical facilitators as they experienced how nursing students' need for facilitation were prioritised during times when nurse facilitators were in majority at the ward. Our results have not shown if this is the case, as it was not the focus in the current study, however it does raise some questions regarding when and how facilitators from the different professions should be present, as it might not be optimal for student learning when one profession is in the majority. Another issue regarding the imbalance of the presence of the facilitators that will need further investigation is the risk for feelings of stress or fear of burn out as described by Reeves and Freeth (2002). The nurses in the present study did not mention stress explicitly and there are probably several reasons for this. It can partly be contributed to the close cooperation within the team of all facilitators, a finding supported by earlier work by Lindqvist and Reeves (2007) where peer support in the form of regular de-briefing sessions were highly valued by the facilitators. Partly it might be an effect of the conscious choice to seek a position as a CTW facilitator which was considered a career step by the nurses. However; these reasons have not been fully explored in the current paper but it raises some interesting questions to be addressed in future studies.

The small sample size (field work $n=8$, interviews $n=8$, focus group $n=4)$ and the time spent in the field $(50 \mathrm{~h})$ might be considered limited. However; due to the combination of methods a sense of data saturation was reached and the decision to leave the field was taken when no further categories emerged during continuous analysis.

\section{Conclusion}

The presented findings have explored a central aspect of interprofessional clinical training by illustrating how nurse facilitators work with interprofessional student teams so that they can learn 
with, from and about each other. The nurse facilitator as a team builder is a new and exciting role for nurses taking on the responsibility of becoming a facilitator. Thus, our findings expand the understanding of nurses' facilitating role as described by Yonge et al. (2007) as the registered nurse responsible for individualised teaching during clinical practice. Future research needs to explore how facilitating nurses balance profession specific and team oriented facilitating within the environment of an interprofessional learning context. Another interesting area would be to direct future studies towards the interprofessional team of facilitators and how they as a team act as role models for the students. It would also be of interest to explore the long term effects of interprofessional education on collaboration and team work skills when IPE students commence their professional careers.

\section{Declaration of interest}

The authors of this paper report no conflicts of interest.

\section{References}

Agar, M., 2008. The Professional Stranger. An Informal Introduction to Ethnography, second ed. Academic Press, San Diego CA.

Anderson, E.S., Cox, D., Thorpe, L.N., 2009. Preparation of educators involved in interprofessional education. Journal of Interprofessional Care 23 (1), 81-94.

Argyris, C., Schön, D., 1974. Theory in Practice: Increasing Professional Effectiveness. Jossey-Bass, San Fransisco, CA

Barr, H., Koppel, I., Hammick, M., Reeves, S., Freeth, D. (Eds.), 2005. Effective Interprofessional Education. Blackwell Publishing.

Begley, C., 2009. Developing interprofessional learning: tactics, teamwork and talk. Nurse Education Today 29 (3), 276-283.

Blumer, H., 1969. Symbolic Interactionism. Perspective and Method. University of California Press, Berkely and Los Angeles, California.

Carlisle, C., Cooper, H., Watkins, C., 2004. "Do none of you talk to each other?" the challenges facing the implementation of interprofessional education. Medical Teacher 26 (6), 542-552.

Carlson, E., Wann-Hansson, C., Pilhammar, E., 2009. Teaching during clinical practice: strategies and techniques used by preceptors in nursing education. Nurse Education Today 29 (5), 522-526.

Cooper, H., Carlisle, C., Gibbs, T., Watkins, C., 2001. Developing an evidence base for interdisciplinary learning: a systematic review. Journal of Advanced Nursing 35 (2), 228-237.

Forte, A., Fowler, P., 2009. Participation in interprofessional education: sn evaluation of student and staff experiences. Journal of Interprofessional Care 23 (1), 58-66.

Freeth, D., Reeves, S., Goreham, C., Parker, P., Haynes, S., Pearson, S., 2001. 'Real life' clinical learning on an interprofessional training ward. Nurse Education Today 21 (5), 366-372.

Glaser, B., Strauss, A., 1967. The Discovery of Grounded Theory: Strategies for Qualitative Research. Aldine, New York.

Hammersley, M., Atkinson, P., 2007. Ethnography Principles in Practice, third ed. Routledge, London \& New York, pp. 1-19.
Hammick, M., Freeth, D., Koppel, I., Reeves, S., Barr, H., 2007. A best evidence systematic review of interprofessional education. Medical Teacher 29 (8), 735-751. BEME guide no.9.

Hannigan, B., 2001. A discussion of the strengths and weaknesses of 'reflection' in nursing practice and education. Journal of Clinical Nursing 10 (2), 278-283.

Hylin, U., Nyholm, H., Mattiasson, A.-C., Ponzer, S., 2007. Interprofessional training in clinical practice on a training ward for healthcare students: a two year follow-up. Journal of Interprofessional Care 21 (3), 277-288.

Jacobsen, F., Fink, A.M., Marcussen, V., Larsen, K., Bæk Hansen, T., 2009. Interprofessional undergraduate clinical learning: aesults from a three year project in a Danish interprofessional training unit. Journal of Interprofessional Care 23 (1), 30-40.

Jarvis, P., 2006. Lifelong learning and the learning society. Towards a Comprehensive Theory of Human Learning, vol. 1. Routledge, London and New York.

Lambert, S.D., Loiselle, C.G., 2008. Combining individual interviews and focus groups to enhance data richness. Journal of Advanced Nursing 62 (2), 228-237.

Lindqvist, S., Reeves, S., 2007. Facilitators' perceptions of delivering interprofessional education: a qualitative study. Medical Teacher 29, 403-405.

Mogensen, E., Elinder, G., Widström, A.-M., Winbladh, B., 2002. Centres for Clinical Education (CCE): developing the health care education of tomorrow a preliminary report. Education for Health 15 (1), 10-18.

Morrison, S., Boohan, M., Jenkins, J., Moutray, M., 2003. Facilitating undergraduate interprofessional learning in healthcare: comparing classroom and clinical learning for nursing and medical students. Learning in Health and Social Care 2 (2), 92-104.

Oandasan, I., Reeves, S., 2005. Key elements of interprofessional education. Part 1: the learner, the educator and the learning context. Journal of Interprofessional Care Supplement 1, 21-38.

O’Halloran, C., Hean, S., Humphris, D., Macleod-Clark, J., 2006. Developing common learning: the new generation project undergraduate curriculum model. Journal of Interprofessional Care 20 (1), 12-28.

Pellatt, G., 2002. Ethnography and reflexivity: emotions and feelings in fieldwork. Nurse Researcher 10 (3), 28-37.

Ponzer, S., Hylin, U., Kusoffsky, A., Lauffs, M., Lonka, K., Mattiasson, A.C., Nordström, G., 2004. Interprofessional training in the context of clinical practice: goals and students' perceptions on clinical education wards. Medical Education 38 (7), 727-736.

Reeves, S., Freeth, D., 2002. The London Training Ward: an innovative interprofessional learning initiative. Journal of Interprofessional Care 16 (1), 41-52.

Reeves, S., Freeth, D., McCrorie, P., Perry, D., 2002. "It teaches you what to expect in future...":interprofessional learning on a training ward for medical, nursing, occupational therapy and physiotherapy students. Medical Education 36 (4), 337-344.

Schön, D., 1987. Educating the Reflective Practitioner. Jossey-Bass, San Fransisco, CA.

Topping, K.J., 1996. The effectiveness of peer tutoring in further and higher education: a typology and review of the literature. Higher Education 32, $321-345$.

Wahlström, O., Sanden, I., 1998. Multiprofessional training ward at Linkoping University: early experience. Education for Health: Change in Learning and Practice 11 (2), 225-231.

Wahlström, O., Sandén, I., Hammar, M., 1997. Multiprofessional education in the medical curriculum. Medical Education 31 (6), 425-429.

World Health Organization, 2006. World Health Report 2006: Working Together for Health. World Health Organization, Geneva.

Yonge, O., Billay, D., Myrick, F., Luhanga, F., 2007. Preceptorship and mentorship: not merely a matter of semantics. International Journal of Nursing Education Scholarship 4 (1) Article 19. 